\title{
The safety of new oral anticoagulants for ischemic stroke and systemic embolism prevention in females with atrial fibrillation
}

\author{
Despina-Manuela Toader ${ }^{1,2}$, Ileana Neaca ${ }^{3}$, Alina Paraschiv², Rodica Musetescu ${ }^{4}$ \\ ${ }^{1}$ EuroEchoLab, Craiova, Romania \\ ${ }^{2}$ Cardiology Center, Emergency Hospital, Craiova, Romania \\ ${ }^{3}$ Sanocare Clinic, Craiova, Romania \\ ${ }^{4}$ Faculty of Medicine, University of Medicine and Pharmacy, Craiova, Romania
}

\begin{abstract}
The prevalence of atrial fibrillation is lower in females than in men, but the risk of stroke and systemic thromboembolism is comparable or even higher. Administration of anticoagulant therapy does not modify this difference. Two classes of non-vitamin $\mathrm{K}$ antagonist oral anticoagulants were studied in atrial fibrillation: direct thrombin inhibitors, like Dabigatran, and activated factor X inhibitors, like Rivaroxaban, Apixaban and Edoxaban. Response to oral anticoagulants could differ between the gender. This medication was evaluated in phase III randomized controlled trials. Non-vitamin $\mathrm{K}$ antagonist oral anticoagulants have been proved more efficacious than Warfarin for stroke and systemic embolism prevention in women, but conclusions regarding the safety and the bleeding are heterogeneous. As in men, before prescribing a NOAC to a female with $\mathrm{AF}$, the stroke and the bleeding risk have to be carefully estimated. It is important that future studies to be targeted on comparison between of non-vitamin $\mathrm{K}$ antagonist oral anticoagulants versus Warfarin in females with non-valvular atrial fibrillation
\end{abstract}

Keywords: non-VKA oral anticoagulants, atrial fibrillation, females, safety

\author{
Abbreviations \\ $\mathrm{AF}$ - atrial fibrillation \\ $\mathrm{CKD}$ - chronic kidney disease \\ $\mathrm{CrCl}$ - creatinine clearance \\ CYP3A4 - cytochrome P450 3A4 \\ Factor $\mathrm{Xa}$ - activated factor $\mathrm{X}$ \\ GI - gastrointestinal
}

ICH - intracranial hemorrhages

INR: International normalized ratio

NOACs - non-VKA oral anticoagulants

P-gp - permeability glycoprotein

TTR - time into therapeutic range

VKAs - vitamin K anticoagulants

\section{INCIDENCE AND PREVALENCE OF ATRIAL FIBRILLATION}

The risk of stroke in patients with atrial fibrillation (AF) is approximately $20-30 \%$ of all strokes $[1,2]$. The incidence of AF roughly doubled for every 10-year in the Framingham Heart Study. AF is 1.2 times more frequent in men compared to women [3]. Framingham Heart Study enrolled 5,209 patients (2,336 men and 2,873 women), 3062 years of age [3]. This study reported that arterial hypertension, diabetes, congestive heart failure, coronary artery disease, and valvular heart disease were independent risk factors for AF [3]. The prevalence of AF ranged between 0.5 and $1 \%$ in developed countries and increases with age. The prevalence between 50 and 59 years is $0.5 \%$ and rises to $9 \%$ between 80 and 89 years [4,5].

In 1998, investigators from the Framingham Heart Study established that AF increased mortality. They reported a 1.5 -fold increase in the men's risk of death and 1.9-fold in women, adjusting for clinical risk factors [3]. 
Women have a lower prevalence of AF at every age compared with men $[8,11]$, but early trials reported higher rates of thromboembolic events in women compared to men [6].

\section{AF AND STROKE IN WOMEN}

The link between female sex and stroke varies across populations and age groups [11,12].

In the ATRIA study, young women (under 65 years of age) had a lower risk of stroke than men. In older age ( $\geq 75$ years), the risk was $10-20 \%$ higher than in men of similar age and was not affected by the use of Warfarin [9]. The trial results suggested that the female gender is a risk factor for stroke, closely linked to age and other major risk factors [9-11].

The women aged $<65$ years with 'lone' AF have a low annual risk for stroke; therefore, the current European and American guidelines do not recommend anticoagulation therapy for this group $[12,13]$. In a meta-analysis of 30 studies with 4371714 participants, Edim CA and al. found AF to be a significant risk factor for death and cardiovascular disease, more important in women than in men [14]. When AF associates with stroke, cardiac events, and heart failure, all causes mortality, is more pronounced in women than men $[8,13]$, suggesting that women and men experience risk factors for cardiovascular disease differently $[8,15]$. It is unclear what could cause these differences. Response to oral anticoagulants could also differ between genders. Some studies revealed a higher risk of bleeding in women [16].

Gender-related differences in the incidence of stroke due to AF ranges from $20 \%$ to $70 \%$ across the studies and persists after correction for age, risk factors, co-morbidities, and the use of oral anticoagulation [16]. A meta-analysis of 17 reports, which included five randomized controlled trials and 12 prospective observational studies, has shown a 1.3-fold greater risk of AF-related stroke in women, which has not been modified by anticoagulation therapy [17].

The exact mechanism by which female gender may affect predisposition to stroke is not clearly understood [14]. The possibilities are genetics, vascular physiology, and endothelial function. Hormonal influences which modulate the expression of tissue factors are also involved. Other fac- tors are biomarkers linked to prothrombotic processes, factors promoting hypercoagulability. Some studies quote less optimal treatment of underlying cardiovascular disease in females [18]. Hormone replacement therapy may also increase the risk of stroke in women with AF $[13,18]$. The reasons for the differential effect of gender on stroke rates in older women are multifactorial $[13,18]$. The studies described increased amyloid production linked to estradiol metabolism. The prevalence of amyloid atrial cardiomyopathy is higher in older women compared to older men. The explanation could be an arrhythmogenic substrate, which would promote the thromboembolism $[13,18]$. Isolated atrial amyloidosis is found in $>90 \%$ of old females, facilitated by AF duration $[13,18]$.

\section{SYSTEMIC THROMBOEMBOLISM PREVENTION IN FEMALES WITH AF}

Oral anticoagulant therapy is the cornerstone of stroke prevention in patients with AF $[19,20]$.

The non-vitamin $\mathrm{K}$ antagonist oral anticoagulant (NOACs) overcome the limitations of using Warfarin in stroke prevention in this group of patients $[19,20]$. There are two classes of NOACs: direct thrombin inhibitors, such as Dabigatran, and activated factor $\mathrm{X}$ (factor $\mathrm{Xa}$ ) inhibitors, such as Rivaroxaban, Apixaban, and Edoxaban [20].

\section{PHARMACOKINETIC OF NOACS}

DABIGATRAN is a reversible competitive inhibitor of thrombin [20]. Mechanism of action is specifically inhibition of free and bound thrombin cloth and thrombin-induced platelet activation inhibition. The kidneys excrete $80 \%$ of Dabigatran. In consequence, half-life and dosing are kidney function and creatinine clearance $(\mathrm{CrCl})$ dependent [20].

RIVAROXABAN is an inhibitor of factor Xa, resulting in a blockade of intrinsic and extrinsic coagulation pathways. Elimination is through renal and digestive routes [20].

APIXABAN is a reversible inhibitor of free and bound factor Xa. The principal modes of elimination of Apixaban are both digestive (56\%) and renal $(24.5 \%)$ [20].

EDOXABAN inhibits competitive factor Xa, leading to a reduction in thrombin generation and 
thrombus formation. The doses have to adjust in patients with renal impairment [21].

\section{CLINICAL TRIALS WITH NOACS}

Large clinical trials evaluated the NOACs [21]. RE-LY (Randomized Evaluation of Long-term Anticoagulation TherapY) was a prospective, randomized controlled, open-labeled trial that compared the efficacy and safety of $110 \mathrm{mg}$ and 150 mg doses of Dabigatran to Warfarin (INR 2-3) [21]. 18,113 patients were enrolled. Primary endpoints were stroke and systemic embolisms. The dose of $110 \mathrm{mg}$ Dabigatran (1.53\% events/year) was non-inferior $(p<0.001)$ to Warfarin and the dose of $150 \mathrm{mg}$ Dabigatran (1.1\% events/year) was superior to Warfarin $(p<0.001)$ [21]. The rate of major and life-threatening bleeding in the group of $150 \mathrm{mg}$ doses of Dabigatran was similar to Warfarin (3.11\% vs. 3.36\% events/year, respectively, $p$ $=0.31)$. The $110 \mathrm{mg}$ dose of Dabigatran was associated with a $20 \%$ risk reduction $(2.7 \%$ vs. $3.4 \%$ events/year, $p=0.003$ ) [21]. Intracranial hemorrhages $(\mathrm{ICH})$ were significantly lower in both Dabigatran arms (110 mg BID and $150 \mathrm{mg}$ BID) than it was in Warfarin arm $(0.23 \%, 0.35 \%$, and $0.74 \%$ events/year respectively, $\mathrm{p}<0.001$ for both groups) [21]. $150 \mathrm{mg}$ dose of Dabigatran increased the risk for gastrointestinal (GI) bleeding when compared to Warfarin $(1.51 \%$ and $1.02 \%$ respectively, $\mathrm{p}<0.001)$, and the $110 \mathrm{mg}$ dose of Dabigatran was similar to Warfarin $(1.12 \%$ and $1.02 \%$ respectively, $\mathrm{p}=0.43$ ). The risk of bleeding with Dabigatran depended on age. Age $>75$ years is also directly related to the risk of strokes and bleeds in AF patients [21].

ROCKET-AF (Rivaroxaban Once-daily oral direct factor Xa inhibition compared with vitamin $\mathrm{K}$ antagonism for prevention of stroke and Embolism Trial in Atrial Fibrillation) was a prospective, randomized, double-blind trial, which compared Rivaroxaban and Warfarin in patients with nonvalvular AF [22]. 14,264 patients were enrolled. Patients were randomized to receive $20 \mathrm{mg}$ /day doses of Rivaroxaban $(15 \mathrm{mg} /$ day if the creatinine clearance is $30-49 \mathrm{ml} / \mathrm{min}$ ) or Warfarin (target INR: between 2 and 3) [22]. The primary endpoints were stroke and systemic embolism. ROCKET AF trial enrolled patients with a higher risk of stroke than other trials with NOACs [13]. Rivaroxaban was non-inferior to Warfarin with respect to the primary endpoint ( $2.1 \%$ vs. $2.4 \%$ respectively, for non-inferiority $\mathrm{p}<0.001)$ [22]. There was no difference between the rates of major and clinically significant non-major bleeding rates between Rivaroxaban and Warfarin groups (14.9\% vs. $14.5 \%$ events, respectively $\mathrm{p}=$ non-significant). In addition, the rate of ICH was significantly lower in the Rivaroxaban group $(0.5 \%$ and $0.7 \%$ events/year, $p=0.02)$ [22].

ARISTOTLE (Apixaban for Reduction in Stroke and Other Thromboembolic Events in Atrial Fibrillation) study enrolled 18,201 patients with nonvalvular AF. They received Apixaban (5 mg, twice a day) or Warfarin [23]. Stroke and systemic embolism occurred at a rate of $1.25 \%$ events per year in the Apixaban group and $1.60 \%$ per year in the Warfarin group (HR $=0.79$; 95\% CI: 0.66$0.95 ; p=0.01$ ) [23]. Patients in this study who had two or more of the following risk factors: age $\geq 80$ years, body weight $\leq 60 \mathrm{~kg}$, or a serum creatinine level $\geq 1.5 \mathrm{mg}$ per deciliter, were treated with 2.5 $\mathrm{mg}$ Apixaban BID (instead of $5 \mathrm{mg}$ BID). The primary composite endpoint, stroke or systemic embolism, occurred in $1.27 \%$ patients in the Apixaban arm and $1.6 \%$ patients in the Warfarin $\operatorname{arm}(\mathrm{p}<0.001$ for non-inferiority, $\mathrm{p}=0.01$ for superiority). According to the results, Apixaban was superior to Warfarin in preventing stroke and systemic embolisms in patients with nonvalvular AF and also in all-cause mortality (3.52\% vs. 3.94\%, p = 0.047) [14]. Rates of major bleeding events in Apixaban and Warfarin groups were similar, but, unlike other NOACs, GI bleeding rate did not increase with Apixaban relative to Warfarin [14]. Major bleeding occurred less in the Apixaban arm (2.13\%) than the Warfarin arm $(3.09 \%)(p<0.001)$. The $\mathrm{ICH}$ rate was $0.33 \%$ event/year in the Apixaban group and $0.80 \%$ event/year in the Warfarin group $(\mathrm{p}<0.001)$ [23].

AVERROES (Apixaban Versus Acetylsalicylic Acid to Prevent Stroke in Atrial Fibrillation Patients Who Have Failed or Are Unsuitable for Vitamin K Antagonist Treatment) was a double-blind, randomized trial including 5,599 patients with $\mathrm{AF}$ for whom vitamin $\mathrm{K}$ antagonist therapy was inappropriate [24]. The patients received Apixaban (5 $\mathrm{mg}$, twice a day) or Aspirin (80-325 mg). The rate of stroke or systemic embolism was $1.6 \%$ in the Apixaban group and $3.7 \%$ in the Aspirin group (HR $0.45,95 \%$ CI $0.32-0.62, \mathrm{p}<0.001$ ) [24]. The 
trial early terminated because it demonstrated a significant benefit of Apixaban vs. Warfarin. There was no significant difference in major bleeding rates between Apixaban and Aspirin groups. Patients tolerated Apixaban better than Aspirin [24].

ENGAGE AF TIMI 48 (Effective Anticoagulation with Factor Xa Next Generation in Atrial Fibrillation-Thrombolysis in Myocardial Infarction 48) was a randomized, double-blind trial comparing Edoxaban vs. Warfarin for thromboembolism and stroke prophylaxis in nonvalvular AF [25]. 21,105 subjects were randomized to a dose of 60 $\mathrm{mg}$ daily (30 mg daily of Edoxaban if any of the following characteristics were present: reduced $\mathrm{CrCl}: 30-50 \mathrm{~m} / \mathrm{min}$, bodyweight $<60 \mathrm{~kg}$, or concomitant use of Verapamil, Quinidine, or Dronedarone). The primary endpoint was systemic embolism and stroke. The primary endpoint annual rate was $1.50 \%$ with Warfarin when compared to $1.18 \%$ with $60 \mathrm{mg}$ Edoxaban ( $\mathrm{p}=0.001$ for non-inferiority) and $1.61 \%$ with $30 \mathrm{mg}$ Edoxaban ( $p=0.005$ for non-inferiority) [25]. The annual rate of major bleeding was $3.43 \%$ in Warfarin, $2.75 \%$, and $1.61 \%$ for $60 \mathrm{mg}$ and $30 \mathrm{mg}$ Edoxaban treatment, respectively ( $p<0.001$ for both doses). Both doses of Edoxaban have shown to be as efficient as Warfarin for systemic embolism and stroke prophylaxis in nonvalvular AF. They were associated with significantly lower rates of bleeding and death from cardiovascular causes. On the other hand, GI bleeding rates were significantly higher in Edoxaban $60 \mathrm{mg}$ group than the Warfarin group. ( $1.51 \%$ vs $1.23 \%$; $p=0.03)$ [25]. Overall, Edoxaban's major bleeding rates are lower than Warfarin's, although the high-dose Edoxaban ( $60 \mathrm{mg}$ /day) had higher GI bleeding rates than Warfarin [25].

\section{FEMALES IN CLINICAL TRIALS WITH NOACS}

The risk of $\mathrm{AF}$ varies according to clinical and demographic characteristics [26]. Patients with AF are at a 5-6 higher risk of stroke than those in sinus rhythm, especially females $[12,14,15]$.

The proportion of women in trials with NOACs was approximately 40\% [26] (Table 1). 6,599 (36.4\%) women were enrolled in RELY trial: 2.150 (35.7\%) received $110 \mathrm{mg}$ Dabigatran and 2.236 (36.8\%) $150 \mathrm{mg}$ Dabigatran. 2.213 (36.7\%) of women received Warfarin. NOACs showed simi- lar or superior efficacy in stroke prevention compared to Warfarin, but the stroke rate remains higher in women than in men [27] (Table 2).

TABLE 1. Women in clinical trials with NOACs

\begin{tabular}{|l|c|c|c|c|c|}
\hline & RE-LY & ROCKET & ARISTOTLE & AVERROES & $\begin{array}{c}\text { ENGAGE } \\
\text { AF TIMI } \\
\mathbf{4 8}\end{array}$ \\
\hline Women & $\begin{array}{c}6,599 \\
(36.4 \%)\end{array}$ & $\begin{array}{c}5,663 \\
(39.7 \%)\end{array}$ & $\begin{array}{c}6,416 \\
(35.3 \%)\end{array}$ & $\begin{array}{c}2,321 \\
(41 \%)\end{array}$ & $\begin{array}{c}8,040 \\
(38 \%)\end{array}$ \\
\hline Age & 71.5 & 73 & 70 & & \\
\hline $\begin{array}{l}\text { Mean } \\
\text { CHADS2 }\end{array}$ & 2.1 & 3.5 & 2.1 & & 2.8 \\
\hline $\begin{array}{l}\text { Mean } \\
\text { follow } \\
\text { up }\end{array}$ & 2 years & 707 days & 1.8 years & year & $\begin{array}{c}2.8 \\
\text { years }\end{array}$ \\
\hline TTR\% & 64 & 65 & 62 & & 64 \\
\hline
\end{tabular}

TTR: time into therapeutic range

TABLE 2. Embolic events in women in clinical trials with NOACs

\begin{tabular}{|c|c|c|}
\hline TRIAL & Drug/dose & $\begin{array}{c}\text { Event rates (\%/year) } \\
\text { women / men }\end{array}$ \\
\hline RELY & Warfarin & $2.03 / 1.49$ \\
& Dabigatran $150 \mathrm{mg}$ & $1.14 / 1.10$ \\
& Dabigatran $110 \mathrm{mg}$ & $1.86 / 1.35$ \\
\hline ROCKET- AF & Warfarin & $5.07 / 3.83$ \\
& Rivaroxaban & $4.5 / 3.34$ \\
\hline ARISTOTLE & Warfarin & $1.8 / 1.5$ \\
& Apixaban & $1.4 / 1.2$ \\
\hline AVERROES & Aspirin & $3.99 / 2.28$ \\
& Apixaban & $1.55 / 0.82$ \\
\hline ENGAGE TIMI 48 & Edox $60 \mathrm{mg}$ & $1.76 / 1.45$ \\
& Edox 30 mg & $2.32 / 1.86$ \\
\hline
\end{tabular}

In an analysis from the RE-LY trial, women had a more significant relative risk reduction than men. The rate of major bleeding and ICH were not different between males and females [28]. Plasma concentrations of Dabigatran in female subjects were $\approx 30 \%$ higher than in male subjects [28]. The authors concluded that the risks of major bleeding and ischemic stroke related to Dabigatran concentrations. They did not mention sex differences in the association with the outcomes [28].

A population-based cohort study conducted by Tsadok et al. in Canada between 1999 and 2013 aimed to compare sex differences in use, safety, and effectiveness of Dabigatran in patients with AF [28]. The cohort comprised 31,786 women $(50.4 \%)$ and 31,324 men (49.6\%). The median follow-up was 1.3 years. Women had a higher baseline stroke risk and lower baseline bleeding risk compared with men. Mean CHA2DS2-VASc score was higher in women than men $(3.9 \pm 1.3$ versus $2.6 \pm 1.4 ; p<0.001)$ [28]. Women filled more pre- 
scriptions for the lower Dabigatran dose (adjusted OR, $1.35 ; 95 \%$ confidence interval, 1.24-1.48). Dabigatran $150 \mathrm{mg}$ associated with a lower risk of stroke in women (HR 0.79; 95\% confidence interval, 0.56-1.04). The incidence of stroke did not differ in both doses of Dabigatran.

Women treated with Dabigatran $110 \mathrm{mg}$ dose had lower bleeding rates, and there was a trend toward lower stroke risk reduction than women taking $150 \mathrm{mg}$ dose Dabigatran [28]. The authors concluded that women might benefit more from treatment with Dabigatran $150 \mathrm{mg}$ for stroke reduction than men because they have a higher baseline risk for stroke [28].

ROCKET trial enrolled 5,663 women (39.7\%). The events rate in women with Rivaroxaban was $4.06 \%$ /year compare to $5.07 \%$ /year in the Warfarin group. The annual rate of bleeding in women was higher with Warfarin compare with Rivaroxaban (19.5 vs. $17.9 \%$ ) [28].

ARISTOTLE trial randomized 6,416 (35.3\%) women with AF. These had a similar rate of stroke or systemic embolism but a lower risk of mortality than men. The clinically relevant bleeding in women was lower than in men. The efficacy and safety of Apixaban compared with Warfarin were consistent for both genders [29]. Events rate with Apixaban was $1.4 \%$ /year in women and $1.2 \%$ /year in men. The bleeding rate in women was higher with Warfarin than with Apixaban, without gender differences between Apixaban and Warfarin [29].

In a secondary analysis of the AVERROES trial, Lip et al. purposed to assess Aspirin effect compare to Apixaban effect on ischemic stroke and major bleeding in women compared to men. Females had higher ischemic stroke risk when treated with Aspirin compare with Apixaban (1.55 vs. $3.99 \% / y e a r)$. The advantage of Apixaban vs. Warfarin was comparable in both sexes [30].

NOACs effect may slightly differ in women, but the differences are clinically negligible [31].

\section{FEMALE GENDER AND RISK OF BLEEDING WITH NOACS}

The studies showed that women might have increased NOACs plasma concentrations compared with men. The explanation could be lower body weight or lower $\mathrm{CrCl}$, which would predispose to higher bleeding risk $[28,32]$. Another cause would be the differences in the coagulation and vascular systems induced by sex hormones [28,32].

A meta-analysis of the ARISTOTLE, AVERROES, RE-LY (150 mg), and ROCKET AF trials reported that women treated with NOACs had lower rates of major bleeding than men (OR 0.84, $95 \%$ CI $0.75-0.96, p=0.007)$. In the ROCKET AF trial, women receiving Rivaroxaban or Warfarin had a reduced risk of major bleeding compared with men. (HR 0.82, 95\% CI 0.70-0.95, p = 0.009) [32]. In the ARISTOTLE trial, females also associated a lower risk of major bleeding compared with men (HR 0.74, 95\% CI 0.63-0.87, p=0.002) [32].

\section{ADVANTAGES AND DISADVANTAGES OF NOACS}

\section{Advantages}

- rapid onset and offset of action [20]

- absence of dietary interactions [20]

- fewer drug interactions [20]

- simplifying treatment due to predictable anticoagulant effects; this enables administration of fixed doses without the need for coagulation monitoring [20]

- reduction of stroke and systemic embolic events, hemorrhagic stroke, and all cause-mortality

NOACs have a favorable safety profile compared with Warfarin; however, they may associate an increase in gastrointestinal bleeding [20].

\section{Disadvantages}

- higher cost [20]

- caution in liver and kidney impairment [20]

- contraindication during pregnancy [20]

- lack of clinical efficacy in thromboprophylaxis in the setting of mechanical valves [20]

- in patients with malignant unwellness and antiphospholipid syndrome [20]

Several factors such as age, race, gender, smoking, and diet can lead to inter-individual variability of NOACs [20]. The presence of common genetic variants or drug-drug interactions may contribute to differences between therapeutic answers [20].

\section{THE AGE AND COMORBIDITIES}

Older women (aged $\geq 75$ years) with a previous stroke history and those with renal dysfunction have an increased risk of both ischemic and bleed- 
ing events [33]. All patients with AF aged over 75 years are eligible for anticoagulant therapy if their thromboembolic risk is sufficiently high (CHA2DS2-VASc C2) [33]. In old females, guidelines recommend an assessment of risk bleeding using the HAS-BLED score before prescribing NOACS [34].

Chronic kidney disease (CKD) is also a significant limitation for the NOACs prescription in the older woman. AF is present in $15-20 \%$ of patients with CKD [36,41]. The patients with AF and CKD have an increased risk of morbidity and mortality due to their excessive risk for both thromboembolic and severe bleeding events [36]. The kidneys partly eliminate the NOACs: Dabigatran: $80 \%$, Rivaroxaban $50 \%$, Apixaban $35 \%$, and Edoxaban $27 \%$ [36]. Guidelines usually recommended the Cockroft-Gault formula to estimate $\mathrm{CrCl}$ for NOACs dosage. Initial and subsequent monitoring of renal function at least annually is essential [41-43]. Expert consensus documents indicate anti-Xa NOACs instead of VKAs for elderly patients with a glomerular filtration rate of $15-30 \mathrm{ml} / \mathrm{min}$ [20,41-43]. NOACs in chronic renal disorder ought to be performed with caution, particularly in aged women with moderate $(\mathrm{CrCl} 30-50 \mathrm{ml} / \mathrm{min})$ or severe ( $\mathrm{CrCl} 10-30 \mathrm{ml} / \mathrm{min})$ nephropathy [20,36,41-43]. This class of medication should not use in patients with dialysis or with $\mathrm{CrCl} \leq 15 \mathrm{ml} /$ min $[41,42,43]$. In ARISTOTLE were included patients with a $\mathrm{CrCl}$ of $25-29 \mathrm{ml} / \mathrm{min}$ [23]. Dabigatran $75 \mathrm{mg}$ twice daily (BID) is approved in the USA, but not in Europe, for patients with an estimated clearance of $15-30 \mathrm{ml} / \mathrm{min}[21,35]$. The USA approved Apixaban $5 \mathrm{mg}$ BID in chronic, stable dialysis-dependent patients [35].

Obese females have a higher risk of developing AF than non-obese patients, with a $4 \%$ increase in the risk of AF per unit increase in body mass index. Arterial hypertension, diabetes, and sleep apnea syndrome are often associated with overweight. These factors will further increase the risk of AF [36]. On the other hand, low weight is a bleeding risk factor. Apixaban and Edoxaban dosage should adapt according to weight [41-44].

For weight less than $60 \mathrm{~kg}$, Apixaban should be decreased from 5 to $2.5 \mathrm{mg}$ BID in patients with at least one of age $>80$ years or serum creatinine greater than $133 \mathrm{mmol} / \mathrm{l}$. Edoxaban dose should be decreased from 60 to $30 \mathrm{mg}$ once daily [41-44].
Advanced liver disease is associated with increased bleeding risk, but is also a prothrombotic disorder [36]. In cases of mild or moderate organ impairment, NOACs can be given with caution, changing the dosage. $[41,42,43,44]$. In cases of severe organ impairment (Child-Pugh category C) and cirrhotic patients with Child-Pugh category B or C, Rivaroxaban must not be administered [4144]. Guidelines contraindicate all four NOACs in patients with hepatic disease associated with coagulopathy and clinically relevant bleeding risk, including Child-Turcotte-Pugh C cirrhosis [41-44].

\section{RISK STRATIFICATION}

Before prescribing a NOAC to a patient with $\mathrm{AF}$, both stroke and bleeding risk have to be estimated [37,41-44].

The American Heart Association/American College of Cardiology/Heart Rhythm Society and the European Society of Cardiology recommend using the CHA2DS2-VASc score to predict stroke risk and guide anticoagulation therapy in individuals with AF [41-44].

European Society of Cardiology guidelines included the CHA2DS2-VASc score in 2010, whereas the American Heart Association/American College of Cardiology guidelines included the score in 2014 [41-44] (Table 3).

The CHA2DS2-VASc score evaluates the risk for stroke and transient ischemic attack (Table 4) [41-44]. This was validated using data from the European Heart Survey trial [37].

CHA2DS2-VASc components are: cardiac failure, arterial hypertension, age $\geq 75$ years (doubled), DM, stroke (doubled), vascular disease, age 65-74, and female gender [37, 38, 39]. Patients with a CHA2DS2-VASc score of 0 have a low risk of ischemic stroke, with an annual stroke rate of approximately $1 \%$ or even lower [38]. Some risk factors for thromboembolism are also risk factors for bleeding. These are advanced age, uncontrolled arterial hypertension, history of ischemic heart disease, cerebrovascular disease [37-39].

HAS-BLED score may give prognostic information regarding death and cardiovascular events, not only bleeding risk [40]. The score was first proposed in 2010 after its derivation and validation in the European Heart Survey trial and is recommended by the European Society of Cardiology 
guidelines for bleeding risk assessment (Table 5). Score $\geq 3$ necessitates caution and regular review (Table 6) [40,41]. Advanced age, uncontrolled arterial hypertension, ischemic heart disease, cerebrovascular disease, anemia, concomitant antiplatelet therapy, and previous bleeding are predictors of major bleeding events during anticoagulation [40,41]. Labile INR control, advanced patient age, and concomitant aspirin or nonsteroidal anti-inflammatory drug could also predict bleeding during anticoagulant therapy [40,41]. It is important to focus attention on reversible bleeding risk factors [41-44] (Table 7).

TABLE 3. CHA2DS2-VASC SCORE (according with clinical practice guidelines)

\begin{tabular}{|l|c|}
\hline \multicolumn{1}{|c|}{ Risk factor } & Score (maximum 9*) \\
\hline C - Congestive heart failure & 1 \\
H - Hypertension & 1 \\
A2 - Age75 years or older & 2 \\
D - Diabetes mellitus & 1 \\
S2 - Stroke, transient ischaemic attack & 2 \\
or thromboembolism & 1 \\
V - Vascular disease (prior myocardial & \\
infarction, peripheral artery disease or & \\
aortic plaque) & 1 \\
A - Age 65 to 74 years & 1 \\
Sc - Sex category (i.e. female) & \\
\hline
\end{tabular}

* Maximum score is 9; for age, either the patient is 75 years or older and gets two points, is between 65 and 74 and gets one point, or is under 65 years and does not get any points.

TABLE 4. Annual risk of stroke after $\mathrm{CHA}_{2} \mathrm{DS} \mathrm{S}_{2}-\mathrm{VASC}$ SCORE calculation (according with clinical practice guidelines)

\begin{tabular}{|c|c|}
\hline $\mathrm{CHA}_{2} \mathbf{D S}_{2}$-VASC SCORE & Annual risk of stroke \\
\hline 0 & 0 \\
\hline 1 & 1.3 \\
\hline 2 & 2.2 \\
\hline 3 & 3.2 \\
\hline 4 & 4 \\
\hline 6 & 6.7 \\
\hline
\end{tabular}

TABLE 5. HAS-BLED SCORE (according with clinical practice guidelines)

\begin{tabular}{|l|c|}
\hline \multicolumn{1}{|c|}{ Risk factor } & \multicolumn{1}{|c|}{$\begin{array}{c}\text { Score } \\
\text { (maximum 9*) }\end{array}$} \\
\hline H- Hypertension (systolic BP over 160 & 1 \\
mmHg) & 1 or 2 \\
A - Abnormal liver or renal function & \\
(1 point each) & 1 \\
S- Stroke & 1 \\
B - Bleeding history & 1 \\
L- Labile INRs & 1 \\
E - Elderly (age over 65 years) & 1 or 2 \\
D- Drugs* or alcohol (1 point each) & \\
\hline
\end{tabular}

* Concomitant use of drugs that promote bleeding.

Abbreviations: $B P=$ blood pressure; INR = international normalised ratio

TABLE 6. Annual risk of bleeding after HAS-BLED SCORE calculation (according with clinical practice guidelines)

\begin{tabular}{|c|c|}
\hline HAS-BLED SCORE & Annual risk of bleeding \\
\hline 0 & 0.9 \\
\hline 1 & 3.4 \\
\hline 2 & 4.1 \\
\hline 3 & 5.8 \\
\hline 4 & 8.9 \\
\hline 5 & 9.1 \\
\hline
\end{tabular}

The most recent guidelines indications are:

1. The CHA2DS2-VASc score is recommended for stroke risk prediction in patients with $\mathrm{AF}$. (Class I, level A) $[43,44]$.

2. Bleeding risk scores should be considered in $\mathrm{AF}$ patients on oral anticoagulation who present risk factors for major bleeding. (Class IIa, level B) $[43,44]$.

3. Oral anticoagulation therapy to prevent thromboembolism is recommended for all females with a $\mathrm{CHA}_{2} \mathrm{DS}_{2}$-VASc score of 3 or more (IA) or 2 considering individual characteristics and patient preferences (IIa B) $[43,44]$.

4. Patients at low risk (CHA2DS2-VASc score $0)$ do not benefit from oral anticoagulation therapy therapy and should not be anticoagulated $[43,44]$.

TABLE 7. Modifiable bleeding risk factors (according with clinical practice guidelines)

\begin{tabular}{|c|c|c|c|}
\hline $\begin{array}{l}\text { Modifiable bleeding risk } \\
\text { factors }\end{array}$ & $\begin{array}{l}\text { Potential modifiable } \\
\text { bleeding risk factors }\end{array}$ & $\begin{array}{l}\text { Non-modifiable bleeding } \\
\text { risk factors }\end{array}$ & $\begin{array}{l}\text { Biomarker- based bleeding } \\
\text { risk factors }\end{array}$ \\
\hline $\begin{array}{l}\text { Hypertension (especially when } \\
\text { systolic blood pressure is }>160 \\
\mathrm{mmHg} \\
\text { Labile INR or time in } \\
\text { therapeutic range }<60 \% \text { a } \\
\text { in patients on vitamin } \mathrm{K} \\
\text { antagonists } \\
\text { Medication predisposing to } \\
\text { bleeding, such as antiplatelet } \\
\text { drugs, nonsteroidal anti- } \\
\text { inflammatory drug } \\
\text { Excess alcohol ( } \geq 8 \text { drinks/ } \\
\text { week) }\end{array}$ & $\begin{array}{l}\text { Anaemia } \\
\text { Impaired renal function } \\
\text { Impaired liver function } \\
\text { Reduced platelet count } \\
\text { or function }\end{array}$ & $\begin{array}{l}\text { Agee (> } 65 \text { years), } \\
(\geq 75 \text { years }) \\
\text { History of major bleeding } \\
\text { Previous stroke } \\
\text { Dialysis-dependent kidney } \\
\text { disease or renal transplant } \\
\text { Cirrhotic liver disease } \\
\text { Malignancy } \\
\text { Genetic factors }\end{array}$ & $\begin{array}{l}\text { High-sensitivity troponine } \\
\text { Growth differentiation factor-15 } \\
\text { Serum creatinine / estimated } \\
\mathrm{CrCl}\end{array}$ \\
\hline
\end{tabular}


5. NOACs (Apixaban, Dabigatran, Edoxaban, or Rivaroxaban) are recommended in preference to VKAs (I A) $[43,44]$.

6. The individual patient profile needs to be considered; for example, the renal function needs to be assessed more frequently in older patients ( $\geq 75$ years), frail patients, intercurrent condition (such as infection or cancer), which may affect hepatic or renal function $[43,44]$.

7. Stroke risk and bleeding risk factors should be periodically reassessed $[43,44]$.

As mentioned before, correcting and minimizing modifiable risk factors is of critical importance to minimize the risk of bleeding while on treatment with a NOAC $[43,44]$.

Guidelines do not recommend or indicate caution when associating NOACs with: strong inhibitors of both cytochrome P450 3A4 (CYP3A4), permeability glycoprotein (P-gp) $[43,44]$, strong inducers of P-gp and/or CYP3A4 (such as rifampicin, carbamazepine etc.) $[43,44]$.

Other anticoagulants, platelet inhibitors (e.g., aspirin, clopidogrel, ticlopidine, prasugrel, ticagrelor, others), non-steroidal anti-inflammatory drugs increase the risk of bleeding. Therefore, such combinations should be carefully balanced $[43,44]$.

8 . The assessment of kidney function is recommended in all AF patients to detect kidney disease and correct the dose (Class I, level A) [43,44].

9. All AF patients treated with oral anticoagulation should be considered for at least yearly renal function evaluation to detect chronic kidney disease (Class IIa, level B) [43,44].

\section{SPECIFIC RECOMMENDATIONS FOR PATIENTS WITH RENAL IMPAIRMENT}

Mild to moderate CKD: all four NOACs seem to be safe. Dabigatran $110 \mathrm{mg} /$ daily is recommended in patients with $\mathrm{CrCl}<50 \mathrm{ml} / \mathrm{min}$ at high risk of bleeding [44].

Severe CKD: $\mathrm{CrCl}$ of $15-29 \mathrm{ml} / \mathrm{min}$ : there are no randomized clinical trials data on the use of NOACs for stroke prevention in AF patients with severe CKD or on renal replacement therapy [44].

Doses of Apixaban and Edoxaban must be reduced by $50 \%$ and Rivaroxaban by $25 \%$ in patients with CKD (stage IV, $\mathrm{CrCl}$ of 15-29 $\mathrm{ml} / \mathrm{min}$ ) [44].

$\mathrm{CrCl} \leq 15 \mathrm{ml} / \mathrm{min}$ and on dialysis: Dabigatran, Rivaroxaban, Apixaban, and Edoxaban are not recommended. Studies with NOACs in patients with end-stage renal dysfunction and on dialysis are ongoing [44].

Dabigatran is primarily cleared by kidneys and should not be the NOAC of the first choice in patients with known CKD, especially stage III or higher [44].

$\mathrm{CrCl}$ of $>95 \mathrm{ml} / \mathrm{min}$ : the studies observed a possibly decreased efficacy of Edoxaban $60 \mathrm{mg}$ OD compared with Warfarin was observed; post hoc analyses revealed a similar effect also for Rivaroxaban and Apixaban [44].

After kidney transplantation: there are no data on the use of NOACs

\section{DOSING NOACS IN FEMALES WITH CKD}

Dabigatran 110 mg BID: in patients with $\mathrm{CrCl}<$ $50 \mathrm{ml} / \mathrm{min}$ at high risk of bleeding.

Rivaroxaban low doses: $15 \mathrm{mg}$, Apixaban: 2.5 mg BID or Edoxaban: $30 \mathrm{mg}$ OD (or reduction to $15 \mathrm{mg}$ QD), are approved in Europe for patients with severe CKD (stage IV, $\mathrm{CrCl}$ of $15-29 \mathrm{ml} / \mathrm{min}$ ) $[43,44]$.

In patients on NOACs, renal function has to be monitored every year.

If renal function is impaired $(\mathrm{CrCl} \leq 60 \mathrm{ml} /$ min), six monthly checks are required.

Monitoring scheme for renal impairment detection:

(i) $\mathrm{CrCl} \geq 60 \mathrm{ml} / \mathrm{min}$ (CKD stage I and II) monitor every year

(ii) $\mathrm{CrCl} 30-60 \mathrm{ml} / \mathrm{min}$ (CKD stage III) - monitor every six months in older women ( $>75$ years) or frail patients on Dabigatran

(iii) $\mathrm{CrCl} \leq 30 \mathrm{ml} / \mathrm{min}$ (CKD stage IV) - monitor every three months

Acute illness often transiently affects renal function (infections, acute heart failure), and therefore should trigger re-evaluation $[43,44]$.

Specific recommendations for patients with hepatic impairment: treatment initiation and follow-up necessitate a specialized center and a multidisciplinary team (including a hepatologist and a hematologist) [44]; in AF patients with Child B liver cirrhosis, Rivaroxaban should not be used. Dabigatran, Apixaban and Edoxaban will be used with caution [44]; NOACS are contraindicated in patients with hepatic disease associated with coagulopathy and clinically relevant bleeding risk [44]. 


\section{CONCLUSIONS}

Females with $\mathrm{AF}$ are at increased risk of stroke compare to males.

The phase III clinical studies with Dabigatran, Rivaroxaban, Apixaban, and Edoxaban in women with AF showed that these drugs provide significant reductions in the rate of stroke or systemic embolism, hemorrhagic stroke, all-cause mortality, and intracranial hemorrhage compared with Warfarin. The relative efficacy and safety are consistent across many women with $\mathrm{AF}$, including the

Conflict of interest: none declared

Financial support: none declared

\section{REFERENCES}

1. Alkhouli M, Friedman PA. Ischemic stroke risk in patients with nonvalvular atrial fibrillation: JACC review topic of the week. J Am Coll Cardiol. 2019;74:30503065.

2. Pistoia F, Sacco S, Tiseo C, et al. The epidemiology of atrial fibrillation and stroke. Cardiol Clin. 2016;34:255-268.

3. Benjamin EJ, Levy D, Vaziri SM, D’Agostino RB, Belanger AJ, Wolf PA. Independent risk factors for atrial fibrillation in a populationbased cohort. The Framingham Heart Study. JAMA. 1994 Mar 16;271(11):840-4.

4. Lip GY, Laroche C, Boriani G, Cimaglia P, Dan GA, Santini M, Kalarus Z, Rasmussen LH, Popescu MI, Tica O, Hellum CF, Mortensen B, Tavazzi L, Maggioni AP. Sex-related differences in presentation, treatment, and outcome of patients with atrial fibrillation in Europe: a report from the Euro Observational Research Programme Pilot survey on Atrial Fibrillation. Europace. 2015 Jan;17(1):24-31.

5. Staerk L, Sherer JA, Ko D, et al. Atrial fibrillation: epidemiology, pathophysiology, and clinical outcomes. Circ Res. 2017; 120:1501-1517.

6. Lip GYH. The safety of NOACs in atrial fibrillation patient subgroups A narrative review. Int J Clin Pract. 2019;73(2):e13285.

7. Boriani G, Pettorelli D. Atrial fibrillation burden and atrial fibrillation type: clinical significance and impact on the risk of stroke and decision making for longterm anticoagulation. Vascul Pharmacol. 2016;83:2635

8. Andrade J, Khairy P, Dobrev D, Nattel S. The clinical profile and pathophysiology of atrial fibrillation relationships among clinical features, epidemiology, and mechanisms. Circ Res. 2014; 114:1453-1468.

9. Alan S. G, Hylek EM, Phillips KA, et al. Prevalence of diagnosed atrial fibrillation in adults national implications for rhythm management and stroke prevention: the anticoagulation and risk factors in atrial fibrillation (ATRIA) Study. JAMA. 2001; 285(18):2370-2375.

10. Piccini JP, Simon DN, Steinberg BA, et al. Differences in clinical and functional outcomes of atrial fibrillation in women and men two-year results from the ORBIT-AF registry. JAMA Cardiol. 2016; 1(3):282-291.

11. Lee JM, Kim TH, Cha MJ, Park J, Park JK, Kang KW, Shim J, Uhm JS, Kim J, Park HW, Lee YS, Choi EK, Kim CS, Joung B, Kim JB. Gender-related Differences in Management of Nonvalvular Atrial Fibrillation in an Asian Population. Korean Circ J. 2018 Jun; 48(6):519-528.

12. Ko D, Rahman F, Schnabel RB, Yin X, Benjamin EJ, Christophersen IE. Atrial fibrillation in women: epidemiology, pathophysiology, presentation, and prognosis. Nat Rev Cardiol. 2016 Jun; 13(6):321-32.

13. Kostopoulou A, Zeljko HM, Bogossian H, Ciudin R, Costa F, Heijman J, Kochhaeuser S, Manola S, Scherr D, Sohal M, Wakili R, Wolf M, elderly and those with moderate and mild renal impairment. NOACs have important benefits in safety and bleeding compared with VKA treatment.

There are insufficient data to support higher susceptibility of bleeding with NOACs therapy in women than men, and this assumption necessitates further trials. Guidelines do not recommend a specific NOAC based on patient gender alone. Drug selection should take into consideration individual characteristics.

Irfan G; on the behalf of the DAS-CAM participants-2017-2018. Atrial fibrillation-related stroke in women: Evidence and inequalities in epidemiology, mechanisms, clinical presentation, and management. Clin Cardiol. 2020 Jan;43(1):14-23.

14. Emdin CA, Wong CX, Hsiao AJ, Altman DG, Peters SA, Woodward $\mathrm{M}$, Odutayo AA. Atrial fibrillation as risk factor for cardiovascular disease and death in women compared with men: systematic review and meta-analysis of cohort studies. BMJ. 2016 Jan 19;532:h7013.

15. Marzona I, Proietti M, Farcomeni A, et al. Sex differences in stroke and major adverse clinical events in patients with atrial fibrillation: a systematic review and meta-analysis of 993,600 patients. Int $\mathrm{J}$ Cardiol. 2018;269:182-191.

16. Lip GYH, Rushton-Smith SK, Goldhaber SZ, et al. Does sex affect anticoagulant use or stroke prevention in nonvalvular atrial fibrillation? The prospective global anticoagulant registry in the FIELD-atrial fibrillation. Circ Cardiovasc Qual Outcomes. 2015;8:S12-S20.

17. Camm AJ, Savelieva I. Female gender as a risk factor for stroke associated with atrial fibrillation. Eur Heart J. 2017;38:1480-1484

18. Hirsh BJ, Copeland-Halperin RS, Halperin JL. Fibrotic atrial cardiomyopathy, atrial fibrillation, and thromboembolism: mechanistic links and clinical inferences. J Am Coll Cardiol. 2015;65:2239-2251.

19. Freedman B, Potpara TS, Lip GYH. Stroke prevention in atrial fibrillation. Lancet. 2016;388:806-817.

20. Badarla A. Pharmacology and toxicological studies review on new oral anticoagulants. RRJPTS. 2017;4(2):129.

21. Connolly SJ, Ezekowitz MD, Yusuf S, et al. RE-LY Steering committee and investigators. Dabigatran versus Warfarin in patients with atrial fibrillation. N Engl J Med. 2009;361:1139-51.

22. Patel MR, Mahaffey KW, Garg J, Pan G, Singer DE, Hacke W, Breithardt G, Halperin JL, Hankey GJ, Piccini JP, Becker RC, Nessel CC, Paolini JF, Berkowitz SD, Fox KA, Califf RM; ROCKET AF Investigators. Rivaroxaban versus warfarin in nonvalvular atrial fibrillation. N Engl J Med. 2011 Sep 8;365(10):883-91.

23. Granger CB, Alexander JH, McMurray JJ, et al. ARISTOTLE Committees and investigators. Apixaban versus Warfarin in patients with atrial fibrillation. N Engl J Med. 2011;365:981-92.

24. Connolly SJ, Eikelboom J, Joyner C, et al. AVERROES Steering Committee and Investigators, Apixaban in patients with atrial fibrillation. N Engl J Med. 2011;364:806-17.

25. Giugliano RP, Ruff CT, Braunwald E, et al. ENGAGE AF-TIMI 48 Investigators. Edoxaban versus Warfarin in patients with atrial fibrillation. N Engl J Med. 2013;369:2093-2104.

26. Apostolakis ZA, Konstantinides SV, Gender and the risk of stroke in atrial fibrillation: impact of old and new anticoagulants regimens. Clin Res Cardiol Suppl. 2013;8:38-45.

27. Moseley A, Doukky R, Williams KA, Jaffer AK, Volgman AS. Indirect Comparison of Novel Oral Anticoagulants in Women with 
Nonvalvular Atrial Fibrillation. J Womens Health (Larchmt). 2017 Mar;26(3):214-221.

28. Tsadok MA, Jackevicius CA, Rahme E, et al. Sex Differences in Dabigatran use, safety, and effectiveness in a population-based cohort of patients with atrial fibrillation. Circ Cardiovasc Qual Outcomes. 2015;8:593-599.

29. Vinereanu D, Stevens SR, Alexander JH, et al. Clinical outcomes in patients with atrial fibrillation according to sex during anticoagulation with Apixaban or Warfarin: a secondary analysis of a randomized controlled trial. Eur Heart J. 2015;36(46):3268-75.

30. Lip GYH, Eikelboom J, Yusuf S, et al. Modification of outcomes with Aspirin or Apixaban in relation to female and male sex in patients with atrial fibrillation, A secondary analysis of the AVERROES investigators. Stroke. 2014;45:2127-2130.

31. Renda G, di Nicola M, De Caterina R. Net Clinical Benefit of Non-vitamin K Antagonist Oral Anticoagulants Versus Warfarin in Phase III Atrial Fibrillation Trials. Am J Med. 2015 Sep; 128(9):1007-14.e2.

32. Thompson LE, Maddox TM, Lei L, et al. Sex differences in the use of Oral Anticoagulants for atrial Fibrillation: A report from the National Cardiovascular Data Registry (NCDR) PINNACLE registry, J Am Heart Assoc. 2017;6:e005801.

33. Fay MR, Fitzmaurice DA, Freedman B. Screening of older patients for atrial fibrillation in general practice: current evidence and its implications for future practice. Eur J Gen Pract. 2017;23:246-253.

34. Chao TF, Lip GYH, Liu CJ, et al. Relationship of aging and incident comorbidities to stroke risk in patients with atrial fibrillation. J Am Coll Cardiol. 2018;71:122-132.

35. Lip GYH, Lane DA, Sarwar S. Streamlining primary and secondary care management pathways for stroke prevention in atrial fibrillation. Eur Heart J. 2017 Oct 21;38(40):2980-2982.

36. Carter L, Gardner M, Magee K, et al. An integrated management approach to atrial fibrillation. J Am Heart Assoc. 2016;5(1):e002950.

37. Tomasdottir M, Friberg L, Hijazi Z, et al. Risk of ischemic stroke and utility of CHA2 DS2 -VASc score in women and men with atrial fibrillation. Clin Cardiol. 2019;42:1003-1009.
38. Overvad TF, Nielsen PB, Lip GYH. Treatment thresholds for stroke prevention in atrial fibrillation: observations on the CHA2DS2-VASc score. Eur Heart J Cardiovasc Pharmacother. 2017;3:37-41.

39. Nielsen PB, Overvad TF. Female sex as a risk modifier for stroke risk in atrial fibrillation: using CHA2DS2-VASc versus CHA2DS2-VA for stroke risk stratification in atrial fibrillation: a note of caution. Thromb Haemost. 2020;120(06):894-898.

40. Lip GYH, Frison L, Halperin JL, Lane DA. Comparative validation of a novel risk score for predicting bleeding risk in anticoagulated patients with atrial fibrillation The HAS-BLED (hypertension, abnormal renal/liver function, stroke, bleeding history or predisposition, labile INR, elderly, drugs/alcohol concomitantly) score. JACC. 2011;57(2):173-180.

41. Kirchhof P, Benussi S, Kotecha D, et al. ESC Scientific Document Group. 2016 ESC Guidelines for the management of atrial fibrillation developed in collaboration with EACTS. Eur Heart J. 2016; 37:2893-2962.

42. Steffel J, Verhamme P, Potpara TS, et al. ESC scientific document group. The 2018 European Heart Rhythm Association practical guide on the use of non-vitamin $\mathrm{K}$ antagonist oral anticoagulants in patients with atrial fibrillation. Eur Heart J. 2018:39:1330-1393.

43. January CT, Wann LS, Calkins H, et al. 2019 AHA/ACC/HRS focused update of the 2014 AHA/ ACC/HRS Guideline for the management of patients with atrial fibrillation. Circulation. 2019;140:e125e151.

44. Hindricks G, Potpara T, Dagres N, Arbelo E, Bax JJ, BlomströmLundqvist C, Boriani G, Castella M, Dan GA, Dilaveris PE, Fauchier L, et al.; ESC Scientific Document Group. 2020 ESC Guidelines for the diagnosis and management of atrial fibrillation developed in collaboration with the European Association for Cardio-Thoracic Surgery (EACTS). Eur Heart J. 2021 Feb 1;42(5):373-498. 